doi: $10.15407 /$ ujpe61.10.0917

A.V. SACHENKO, V.P. KOSTYLYOV, V.M. VLASIUK, R.M. KORKISHKO, I.O. SOKOLOVS'KYI, V.V. CHERNENKO

V.E. Lashkaryov Institute of Semiconductor Physics, Nat. Acad. of Sci. of Ukraine (41, Prosp. Nauky, Kyiv 03680, Ukraine; e-mail: sach@isp.kiev.ua)

\title{
FEATURES IN THE FORMATION
}

OF A RECOMBINATION CURRENT IN THE SPACE

PACS 73.50.Pz, 88.40.jj CHARGE REGION OF SILICON SOLAR CELLS

\begin{abstract}
Dark I-V curves of silicon solar cells with various Shockley-Reed-Hall lifetimes have been studied. The lifetimes are determined from the short-circuit-current internal quantum yield. The recombination currents in the space charge region (SCR) are found to be formed within time intervals that are at least an order of magnitude shorter than the charge-carrier bulk lifetime. This effect can be associated with a high defect concentration (and, therefore, a high deep-level concentration) in the SCR of examined Si structures. The parameters of deep centers that are responsible for the recombination in the SCR have been evaluated.

Keywords: recombination current, space charge region, silicon solar cells, deep recombination level.
\end{abstract}

\section{Introduction}

The research of the rectifying properties of semiconductors that are connected with the presence of space charge regions (SCRs) were started at the Institute of Physics of the AS of the UkrSSR as long ago as in the pre-World War II times [1]. In the post-war period, they were essentially extended, in particular, onto the case of high excitation levels $[2,3]$. At the same time, it was found that the recombination currents in silicon diodes at sufficiently low excitation levels are determined by the recombination that occurs in the SCR [4]. In the case of silicon solar cells (SCs) with diffusion $p-n$ junctions, which operate under the AM1.5 conditions, the influence of the recombination in the SCR on SC parameters can be neglected. However, in the threshold Si photo diodes operating at a low illumination, the contribution of the recombination is substantial [5,6]. Moreover, the account for the recombination turns out rather often to be important at the measurements of low-signal photovoltages. In SCs with rear metallization, the recombination in the SCR can also considerably confine the short-circuit current that is measured at low illumination values $[7,8]$. Earlier, we paid attention to that the recom-

(C) A.V. SACHENKO, V.P. KOSTYLYOV, V.M. VLASIUK, R.M. KORKISHKO, I.O. SOKOLOVS'KYI, V.V. CHERNENKO, 2016

ISSN 2071-0194. Ukr. J. Phys. 2016. Vol. 61, No. 10 bination rates in SCs with rear metallization at low illumination levels are too large and do not correlate with large bulk lifetimes.

In this work, making the assumption that the recombination in the SCR is governed by a single deep level, its dependence on the lifetime $\tau_{\mathrm{SC}}$ that is realized in a narrow SCR interval, where recombination in the SCR is actually formed, is calculated. At the same time, the quantity $\tau_{\mathrm{SC}}$ is determined from the experimental dark current-voltage characteristics (IVCs) measured for silicon SCs with diffusion $p-n$ junctions and the bases of the $n$ - and $p$-types. The obtained result is compared with the lifetime in the quasineutral base region, $\tau_{b}$. The latter parameter is determined from the spectral dependences measured for the short-circuit-current internal quantum yield. Finally, the dark IVCs measured for silicon SCs are used to evaluate the parameters of deep centers that govern the rate of recombination in the SCR; in particular, these are their energy depth, concentration, and capture cross-sections for electrons and holes.

\section{A Model for the Rate of Recombination in the SCR}

As was said above, this model was developed under the assumption that the rate of recombination in the $\mathrm{SCR}, V_{\mathrm{SC}}$, is determined by a single deep level with 


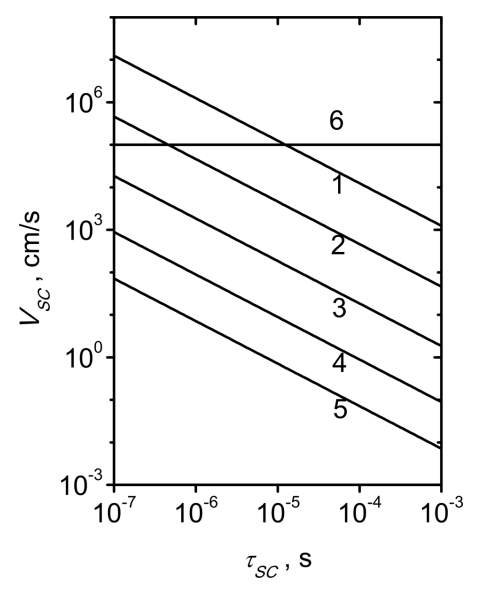

Fig. 1. Dependences of the rate of recombination the in SCR, $V_{\mathrm{SC}}$, on the Shockley-Reed-Hall lifetime in the SCR, $\tau_{\mathrm{SC}}$. The parameter values are $n_{0}=3 \times 10^{15} \mathrm{~cm}^{-3}, b=1$, and $E_{t}=0$. $\Delta n=10^{4}$ (1), $10^{7}$ (2), $10^{10}$ (3), $10^{13}$ (4), and $10^{16} \mathrm{~cm}^{-3}$ (5). Curve 6 corresponds to $V_{\mathrm{SC}}=10^{5} \mathrm{~cm}^{-3} / \mathrm{s}$

the concentration $N_{t}^{*}$, the energy position $E_{t}$ with respect to the energy gap midpoint, and the crosssections of electron, $\sigma_{n}$, and hole, $\sigma_{p}$, capture. Under those assumptions, the expression for the rate of recombination in the SCR in a base of the $n$-type looks like

$V_{\mathrm{SC}}=\int_{y_{p n}}^{y_{w}} \frac{L_{\mathrm{D}} C_{n} C_{p} N_{t}^{*}\left(n_{0}+\Delta n\right) d y}{\left(R_{n}+R_{p}\right)(-y)^{1 / 2}}$.

Here,

$R_{n}=C_{n}\left(\left(n_{0}+\Delta n\right) \exp (y)+n_{i}(T) \exp \left(E_{t} / k T\right)\right)$, $R_{p}=C_{p}\left((p 0+\Delta n) \exp (-y)+n_{i}(T) \exp \left(-E_{t} / k T\right)\right)$,

$y_{w}$ and $y_{p n}$ are the dimensionless band bending at the SCR boundaries with the quasineutral bulk and the emitter, respectively; $L_{\mathrm{D}}$ is the Debye scattering length; $C_{n}=V_{n T} \sigma_{n} ; C_{p}=V_{p T} \sigma_{p} ; V_{n T}$ and $V_{p T}$ are the average thermal velocities of electrons and holes, respectively; $n_{0}$ and $p_{0}$ are the equilibrium bulk concentrations of electrons and holes, respectively; $\Delta n$ is the excess concentration of electron-hole pairs; $y$ the dimensionless electrostatic potential in the SCR; $n_{i}(T)$ the concentration of intrinsic charge carriers in silicon, $k$ the Boltzmann constant, and $T$ the absolute temperature in Kelvins.

Note that expression (1) is valid not only when the quantity $N_{t}^{*}$ is constant in the SCR, but also when it weakly changes in vicinities of energies of about $k T$ near the plane, at which the integrand in Eq. (1) has a maximum. We assume the last condition to be satisfied. Then, as usual, the quantity $\tau_{\mathrm{SC}}$ can be taken to equal $\left(C_{p} N_{t}^{*}\right)^{-1}$ in a base of the $n$-type and $\left(C_{n} N_{t}^{*}\right)^{-1}$ in a base of the $p$-type.

Figure 1 demonstrates the calculated dependences of the recombination rate in the $\mathrm{SCR}, V_{\mathrm{SC}}$, on the quantity $\tau_{\mathrm{SC}}$. The curves are parametrized by the value of $\Delta n$. One can see from this figure that two conditions must be satisfied for the magnitude of $V_{\mathrm{SC}}$ to be not less than $10^{5} \mathrm{~cm} / \mathrm{s}$ at typical base doping levels of about $3 \times 10^{15} \mathrm{~cm}^{-3}$. First, $\tau_{\mathrm{SC}}$ should not exceed $10^{-5} \mathrm{~s}$. Second, the excitation level should be small enough, namely, less than $10^{10} \mathrm{~cm}^{-3}$.

Note that the values $V_{\mathrm{SC}} \geq 10^{5} \mathrm{~cm} / \mathrm{s}$ were observed in works $[7,8]$. They do not agree with the value $\tau_{b} \approx$ $4 \times 10^{-4} \mathrm{~s}$ corresponding to the bulk diffusion length.

In order to analyze the influence of a non-uniform distribution of the deep-level concentration in the SCR on the dark current (this is a result of the recombination in the SCR) in more details, let us consider a situation where the quantity $N_{t}$ changes along the coordinate $x$ perpendicularly to the junction plane following the law

$N_{t}(x)=N_{1} \exp \left(-\frac{x}{r}\right)+N_{0}$,

where $N_{1}$ is the concentration of the deep recombination level located at the middle of the energy gap and in the plane of $p-n$ junction, $r$ a characteristic distance, at which $N_{t}$ becomes lower by a factor of $e$, and $N_{0}$ the concentration of deep level in the neutral base volume. Considering that the base of the $n$-type is doped to a level of $3 \times 10^{15} \mathrm{~cm}^{-3}$ and neglecting the series resistance for the sake of simplicity, let us write down the expression for the dark current associated with the recombination in the SCR in the form (the case $T=300 \mathrm{~K})$ :

$$
\begin{aligned}
& I(V)=\frac{q}{\tau_{b}} \int_{0}^{w} \frac{N_{t}(x)}{N_{0}} \times \\
& \times \frac{\left(n_{0}+\Delta n(V)\right) \Delta n(V) d x}{\left(n_{0}+\Delta n(V)\right) \exp (y(x))+\Delta n(V) \exp (-y(x))},
\end{aligned}
$$

where $q$ is the elementary charge,

$$
\begin{aligned}
& \Delta n(V)=\frac{n_{i}(300)^{2}}{n_{0}}\left(\exp \left(\frac{q V}{0.0259}\right)-1\right), \\
& w=1.15 \times 10^{-5}\left(-y_{p n}-V / 0.0259\right)^{1 / 2}
\end{aligned}
$$

ISSN 2071-0194. Ukr. J. Phys. 2016. Vol. 61, No. 10 
is the SCR thickness (in centimeters),

$y(x)=\left(y_{p n}+V / 0.0259\right)\left(1-\frac{x}{w}\right)^{2}$

is the dimensionless band bending in the depletion layer, and $V$ the applied voltage. In further calculations, we took $y_{p n}=-26$.

In Fig. 2, the theoretical $N_{1}(x)$ dependences and the normalized integrands in Eq. (3) are plotted. The latter are responsible for the spatial dependence of the recombination in the SCR at various applied voltages and are plotted for the parameter values $N_{1}=10^{14} \mathrm{~cm}^{-3}$ and $N_{0}=10^{13} \mathrm{~cm}^{-3}$. Curves 1 to 4 are calculated for the parameter $r=10^{-4}, 6 \times 10^{-5}$, $3 \times 10^{-5}$, and $10^{-5} \mathrm{~cm}$, respectively. The $V$-values for curves $1^{\prime}$ to $3^{\prime}$ amount to $0.1,0.2$, and $0.3 \mathrm{~V}$, respectively. It is evident that the dependence $N_{t}(x)$ decreases most strongly in the interval $0 \leq x \leq w$ at $r=10^{-5} \mathrm{~cm}$. One can also see that the growth of $V$ gives rise to a shift of the maxima in the dependences of the recombination rate in the SCR toward smaller $x$-values. Finally, this process stimulates an increase of the dark recombination current.

Figure 3 exhibits the dependences $I(V)$ that were calculated using formula (3) for various values of $r$ and $N_{1}$. Curve 1 corresponds to the case where $N_{1}=0$, the deep level concentration is constant everywhere and equals $10^{13} \mathrm{~cm}^{-3}$, and $\tau_{\mathrm{SC}}=\tau_{b}$. The corresponding recombination current associated with the recombination in the SCR is the lowest, and the coefficient of IVC nonideality is close to a value of 2 in the applied voltage interval from 0.1 to $0.4 \mathrm{~V}$. It can be seen from the fitting formula for the calculated current:

$I_{k}(V)=I_{0}\left(\exp \left(\frac{V}{0.0259 \times 2}\right)-1\right)$,

where $I_{0}$ is the saturation current (curve 7). However, at $V \geq 0.4 \mathrm{~V}$, the slope of the curve $I(V)$ increases, i.e. the magnitude of $n$ becomes smaller than two.

Curves 2 to 5 are plotted for $N_{1}=10^{14} \mathrm{~cm}^{-3}$. The corresponding $r$-values are $10^{-5}, 3 \times 10^{-5}, 6 \times 10^{-5}$, and $10^{-4}$. One can see that curves 4 and 5 practically coincide, and curve 3 is located nearly to them. At $r=10^{-5} \mathrm{~cm}$, the current is lower than in the previous case; the section with $n \approx 2$ is also shorter. Finally, curve 6 corresponds to the case $N_{1}=10^{15} \mathrm{~cm}^{-3}$ and $r=10^{-5} \mathrm{~cm}$. Here, the current is maximum, but the

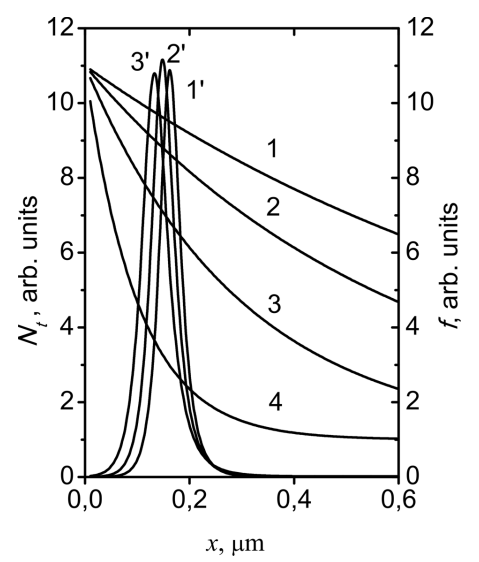

Fig. 2. Dependences $N_{t}(x)$ and normalized dependences $f(x)$ for $V=0.1(1), 0.2(2)$, and $0.3 \mathrm{~V}$ (3)

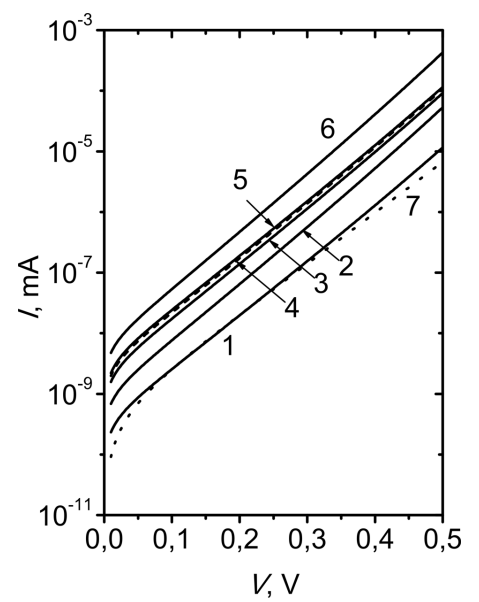

Fig. 3. Dependences of the recombination current in the SCR on the applied voltage. See further explanations in the text

length of the section with $n \approx 2$ is shorter than in the case $r=10^{-4} \mathrm{~cm}$.

Attention is attracted by the fact that, sooner or later, the magnitude of $I(V)$ for all curves plotted in Fig. 3 starts to grow more strongly than $\exp (V /(0.0259 \times 2))$, with the curve slope being larger for smaller $r$-values. The analysis of this phenomenon in the case where $N_{1} \gg N_{0}$ demonstrates that it is related to the circumstance that the plane, at which the recombination rate is the highest, i.e. the point $x_{m}$, shifts to the $p-n$ junction plane with a growth of the applied voltage $V$. The value of $N_{t}\left(x_{m}\right)$ increases at that, and so does the dark current. The smaller the value of $r$, the more pronounced is this effect (see curves 2 and 4). 


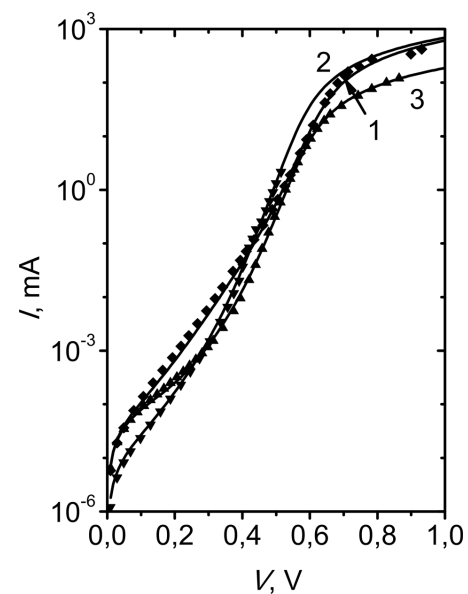

Fig. 4. Dependences of the dark current in silicon SCs with the base of the $n$-type: theory (curves) and experiment (symbols)

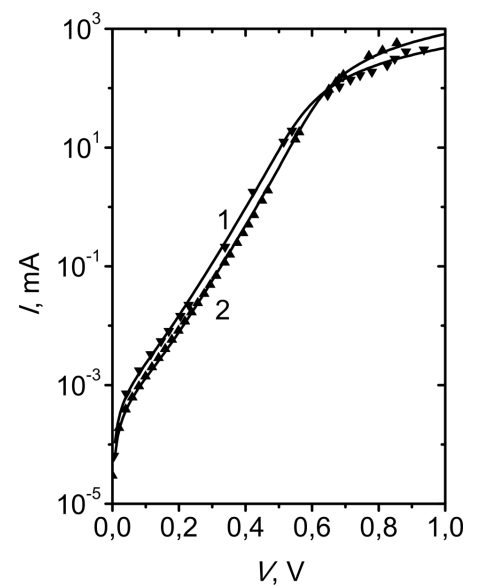

Fig. 5. Dependences of the dark current in silicon SCs with the base of the $p$-type: theory (curves) and experiment (symbols)

Concerning the condition of weak gradient for the dependence $N_{t}(x)$ in the regions, where the integrand in the expression for the recombination rate in the SCR has a maximum, it is satisfied in two cases: at $r=6 \times 10^{-5}$ and $10^{-4} \mathrm{~cm}$ (see curves 4 and 5 ). For curves 2, 3, and 6 , this condition is not obeyed.

Hence, our analysis shows that the assumption of weak gradient for the distribution $N_{t}(x)$-it allows the $N_{1}$-value to be used in calculations-is valid for the exponential recession of $N_{t}(x)$, provided that $r \geq w$. At the same time, at $x \geq 3 \times 10^{-4} \mathrm{~cm}$, the quantity $N_{t}(x)$ decreases practically to a value of $N_{0}$, which governs the bulk lifetime.

\section{Research and Simulation of Dark IVCs}

Experimental specimens were fabricated on the basis of silicon wafers with the $n$ - or $p$-type of conductivity. They had either the $p^{+}-n-n^{+}$or $n^{+}-p-p^{+}$structure, respectively. The front $p^{+}-n$ and isotype rear $n-n^{+}$junctions were formed, by using the boron diffusion into phosphorus-doped wafers, whereas the $n^{+}-p$ and $p-p^{+}$junctions were formed with the use of the phosphorus diffusion into boron-doped wafers. Layers of thermal silicon dioxide about $110 \mathrm{~nm}$ in thickness were used as an antireflecting coating.

Three experimental SC specimens (two with the base of the $p$-type, and one with the base of the $n$ type) were characterized by short or relatively short Shockley-Reed-Hall lifetimes in their emitters and bases. In addition, they had rather a deep location of the $p-n$ junction, which resulted in their low photoconversion efficiency. Another two SC specimens (with the base of the $n$-type) had large ShockleyReed-Hall lifetimes in the base and rather a high photoconversion efficiency. The parameters of all researched specimens are quoted in Table. These SC specimens were used to measure the spectral dependences of the external and internal photocurrent quantum yields, as well as dark IVCs. In particular, Fig. 4 demonstrates the dark IVCs obtained for three $\mathrm{SC}$ specimens with the base of the $n$-type, and Fig. 5 does the same for two specimens with the base of the $p$-type.

The dark IVCs for SCs were simulated, by using the expression

$$
\begin{aligned}
& I(V)=q A\left\{\left[V_{\mathrm{SC}}+D / L_{d} \tanh \left(d / L_{d}\right)+S\right] \times\right. \\
& \left.\times \Delta n(V)+\left(V-I R_{S}\right) / R_{p}\right\},
\end{aligned}
$$

where $I(V)$ is the dark current, $V$ the applied voltage, $A$ the SC area, $D$ the diffusion coefficient for minority charge carriers, $L_{d}$ the diffusion length of minority charge carriers in the bulk, $S$ the surface recombination rate, $R_{S}$ the series resistance, $R_{p}$ the shunt resistance, and

$\Delta n(V)=\frac{n_{i}^{2}(T)}{n_{0}\left(p_{0}\right)}\left[\exp \left(\frac{q V-I R_{S}}{k T}\right)-1\right]$.

As is seen from Fig. 4, the experimental dependences obtained for the SC specimens with the base of the $n$-type agree well with the theoretical curves. Three features should be noted. The first of them consists

ISSN 2071-0194. Ukr. J. Phys. 2016. Vol. 61, No. 10 


\begin{tabular}{|c|r|c|c|c|c|c|c|c|c|}
\hline Specimen & $n_{0}, \mathrm{~cm}^{-3}$ & $d, \mu \mathrm{m}$ & $\tau_{b}, \mu \mathrm{s}$ & $\tau_{\mathrm{SC}} \mu \mathrm{S}$ & $S, \mathrm{~cm} / \mathrm{s}$ & $R_{S}, \Omega$ & $R_{p}, \Omega$ & $\frac{\sigma_{p}}{\sigma_{n}}$ & $E_{t}, \mathrm{eV}$ \\
\hline 1 & $3.1 \times 10^{15}$ & 380 & 25 & 1 & $4 \times 10^{2}$ & 0.5 & $2 \times 10^{6}$ & 0.05 & 0 \\
2 & $3.1 \times 10^{15}$ & 380 & 400 & 4 & $2.6 \times 10^{3}$ & 1 & $8 \times 10^{6}$ & 0.05 & $(-0.05-0.05)$ \\
3 & $3.1 \times 10^{15}$ & 380 & 400 & 4 & $5 \times 10^{2}$ & 1.8 & $1.5 \times 10^{6}$ & 0.07 & $(-0.05-0.05)$ \\
4 & $3 \times 10^{15}$ & 350 & 0.7 & 0.06 & $5 \times 10^{3}$ & 0.8 & $9 \times 10^{4}$ & 40 & 0 \\
5 & $1.6 \times 10^{15}$ & 380 & 17 & 0.3 & $3 \times 10^{2}$ & 0.4 & $1.5 \times 10^{5}$ & 30 & 0 \\
\hline
\end{tabular}

in that the shunt resistance has to be taken into account in order to attain the agreement, although its magnitudes (about $10^{5} \Omega$ ) practically never affect the light IVCs. The second and more important feature is the fact that the value of $\tau_{\mathrm{SC}}$, at which the agreement between the experimental and theoretical curves is achieved, is substantially smaller than $\tau_{b}$. In particular, for specimen 1 , we have $\tau_{b}=25 \mu \mathrm{s}$ and $\tau_{\mathrm{SC}}=1 \mu \mathrm{s}$. However, the most striking difference takes place for specimens 2 and 3 with the base of the $n$-type. In those cases, $\tau_{b}=400 \mu \mathrm{s}$, whereas $\tau_{\mathrm{SC}}$ is close to $4 \mu \mathrm{s}$. The third feature of the SCs with the base of the $n$-type is the fact that the best agreement between the theory and the experiment is attained, when the electron capture cross-section is much larger (approximately by a factor of 20) than the hole capture one. It should also be noted that the parameters governing the recombination current in specimens 2 and 3 (they were fabricated, by using the same technology) practically coincide.

From Fig. 5, one can see that the experimental dependences for the SC specimens with the base of the $p$-type are also in good agreement with the theoretical curves. In this case, for the agreement between the theory and the experiment to be attained, the shunt resistance should be taken into consideration as well. The value of the parameter $\tau_{\mathrm{SC}}$ is also an order of magnitude larger than $\tau_{b}$. However, the best agreement between the experiment and the theory for the SC specimens with the base of the $p$ type is obtained, when the electron capture crosssection is much smaller than the capture cross-section for holes. Note that, for the SC specimens irrespective of the base type, the agreement between the theory and the experiment worsens, when the position of the deep level deviates from the energy gap midpoint.

The concentration of deep levels located in the SCR was estimated to have an order of $10^{14} \mathrm{~cm}^{-3}$. In the
SC specimens with the base of the $p$-type, the strong reduction of the $\tau_{\mathrm{SC}}$-value against the $\tau_{b}$-one may probably be associated with the presence of boronoxygen complexes $[9,10]$. On the other hand, nothing can be said about the nature of this reduction in the specimens with the base of the $n$-type. At the same time, it seems that the SCR, in which the recombination takes place, is very rich for various defects that gives rise to the appearance of deep levels. As a result, there exist and become active in all cases those of them, which bring about the maximum growth of $V_{\mathrm{SC}}$ and the maximum recombination current in the SCR.

\section{Conclusions}

Hence, the results of our researches show that the concentration of the deep levels that are responsible for recombination in the SCR amounts to about $10^{14} \mathrm{~cm}^{-3}$. Their energy position is close to the energy gap midpoint. Electrons are most effectively captured in the specimens with the base of the $n$-type, and holes in the specimens with the base of the $p$ type. Concerning the determination of the nature of centers that are responsible for the recombination in the SCR in silicon SCs, as well as the specification of their parameters, the research of those issues should be continued with the use of other techniques, in particular, photoluminescence.

Our analysis has shown that the presence of sections with the nonideality coefficient close to two in the dark current-voltage characteristics for all studied specimens is not enough to draw a conclusion about the small gradient of the concentration of deep recombination centers in a vicinity of the maximum of the integrand in Eq. (2). The only factor that allows this conclusion to be drawn is rather a long length of this section. By the way, for the examined SC specimens, the length of the section with $n \approx 2$ was large. 
1. V.I. Lyashenko and G.A. Fedorus, Zh. Eksp. Teor. Fiz. 8, 818 (1938).

2. E.I. Rashba and K.B. Tolpygo, The direct voltage-current characteristic of a plane rectifier with large currents, Sov. Phys.-Tech. Phys. 1, 1388 (1956).

3. Z.S. Gribnikov, Radiotekhn. Elektron. 9, 163 (1964).

4. S.C.T. Sah, R.N. Noyse, and W. Shockley, Carrier-generation and recombination in $\mathrm{P}-\mathrm{N}$ junctions and $\mathrm{P}-\mathrm{N}$ characteristics, Proc. IRE 45, 1228 (1957).

5. E.F. Zalewski and C.R. Duda, Silicon photodiode device with $100 \%$ external quantum efficiency, Appl. Opt. 22, 2867 (1983) [DOI: 10.1364/AO.22.002867].

6. A. Rohas, A.R. Paucard, B. Besse et al., Low-noise silicon avalanche photodiodes fabricated in conventional CMOS technologies, IEEE Trans. El. Dev. 49, 387 (2002) [DOI: 10.1109/16.987107].

7. A.P. Gorban, V.P.Kostylyov, A.V. Sachenko, O.A. Serba, I.O. Sokolovs'kyi, and V.V. Chernenko, Effect of floating $p-n$ junctions on the efficiency of silicon back side contact solar cells, Ukr. Fiz. Zh. 55, 784 (2010).

8. A.P. Gorban, V.P.Kostylyov, A.V. Sachenko, O.A. Serba, and V.V. Chernenko, Sensor. Elektron. Mikrosyst. Tekhnol. 1, No. 7, 27 (2010).

9. K. Bothe, R. Sinton, and J. Schmidt, Fundamental boron-oxygen-related carrier lifetime limit in mono- and multicrystalline silicon, Prog. Photovolt. 13, 287 (2005) [DOI: $10.1002 /$ pip.586].
10. K. Bothe and J. Schmidt, Electronically activated boronoxygen-related recombination centers in crystalline silicon, Appl. Phys. 99, 013701 (2006) [DOI: 10.1063/1.2140584].

Received 23.04.16.

Translated from Ukrainian by O.I. Voitenko

А.В. Саченко, В.П. Костильов, В.М. Власюк,

P.М. Коркішко, І.О. Соколовсъкий, В.В. Черненко

ОСОБЛИВОСТІ ФОРМУВАННЯ

РЕКОМБІНАЦІЙНОГО СТРУМУ В ОБЛАСТІ

ПРОСТОРОВОГО ЗАРЯДУ КРЕМНІЕВИХ

СОНЯЧНИХ ЕЛЕМЕНТІВ

$\mathrm{P}$ е $з$ ю м е

Досліджено темнові ВАХ кремнієвих сонячних елементів з різними часами життя Шоклі-Ріда-Холла, які визначались з спектральних залежностей внутрішнього квантового виходу струму короткого замикання. Встановлено, що рекомбінаційні струми в області просторового заряду (ОПЗ) формуються на основі часів життя, менших, принаймні на порядок, за об'ємні часи життя. Це пояснено великою концентрацією дефектів, які приводять до появи глибоких рівнів, в ОПЗ досліджуваних структур кремнію. Оцінено параметри глибоких рівнів, відповідальних за рекомбінацію в ОПЗ. 